a $T$-phase structure. At peak hardness this $T$ phase predominated and a small amount of $S$ was detected. As softening occurred, the $S$ phase increased as a uniform dispersion of lath-shaped particles and the $T$ phase gradually decreased in amount. The $S$ particles appeared to be nucleated homogeneously and were much finer than those present in the ternary alloy.

The effect of silver in promoting $T$-phase precipitation may be related to the fact that small amounts of silver stimulate hardening in aluminium-5 per cent magnesium by precipitating an equilibrium $T$ phase, approximately $\mathrm{Al}_{6} \mathrm{Ag} \mathrm{Mg}_{4}$, as we have found, and which was reported recently by Wheeler et $a l^{10}$. In the present work, using molybdenum radiation, the $\mathrm{X}$-ray reflexions from the small particles were too diffuse to enable us to decide whether the $T$ phase is this compound or $\mathrm{Al}_{6} \mathrm{Cu} \mathrm{Mg} 4$.

Another observation was that the peak hardnesses of the silver-free and silver-containing alloys were closer than might be expected from the marked contrast in the appearance of the precipitates. 'This hardness difference was even less at longer agoing times when there was still a marked disparity between the size and dispersion of the lath-shaped \& particles. This suggests that the ability of dispersions of this kind to retard dislocation movements during plastic deformation is relatively insensitive to the size of the particles. The results may also have practical implications in view of the fact that aluminium -2.5 per cent copper-1.5 per cent magnesium is the age-hardening component of several commercial alloys used for elevated temperature applications. All these aspects are being investigated in more detail.

We thank Mr. B. E. Williams for his contribution to the experimental work.

$$
\begin{aligned}
& \text { J. H. AUld } \\
& \text { J. T. Vietz } \\
& \text { I. J. Polmear }
\end{aligned}
$$

Aeronautical Research Laboratories,

Australian Defence Scientific Service,

Department of Supply, Melbourne.

${ }^{1}$ Polmear, I. J., Nature, 186, 303 (1960).

" Polmear, I. J., J. Inst. Metals, 89, 193 (1960-61).

" Rosenkranz, W., Aluminium, 39, 290, 030, 741 (1963).

${ }^{4}$ Di Russo, E., Alluminio, 33, 505 (1964); ibid., 34, 331 (1965).

s Polmear, I, J., Trans. Met. Soe. Amer, Inst. Merh. Eng., 230, 1331 (1964).

- Polmear, I. J., and Sargant, K. R., Nature, 200, 669 (1963).

Vietz, J. T., Sargant, K. R., and Polmear, I. J., J. Inst. Metals, 92, 327 (1963-64).

- Silcock, J. M., J. Inst. Metals, 89, 203 (1960-61).

Wilson, R. X., and Forsyth, H. J. E., Royal Aireraft Establishment Tech. Rep. 64040 (Nov. 1964).

10 Wheeler, M. J., Blankenburgs, G., and Staddon, R. W., Nature, 207, 746 (1965).

\section{Enhanced Diffusion Rates during the Fatigue of Metals}

ENHANCED diffusion rates during plastic straining or fatigue testing have been the subject of controversy for some time ${ }^{1}$. Conclusive evidence of this phenomenor, notwithstanding an estimate of the effect, has not yet been achieved. However, an investigation recently conducted on the fatigue properties of certain copper alloys at room temperature under unique conditions has allowed confirmation of changes in diffusion rate and also a moasure of this change.

Fatigue tests have been conducted on oxygen-free highconductivity copper specimens possessing a surface-alloyed layer of silver lo a depth of $90 \mu \mathrm{m}$; the silver concentration varied from approximately 4 per cent at the surface to zero at $90 \mu \mathrm{m}$. Specimens were tested in a Wohler-type fatigue machine, operating at 2,880 c.p.m. at a stress-Ievel giving a lotal life of $10^{7}$ cycles. After failure, sections were taken to allow measurement of the radial distribution of the silver by means of a 'Cameca' electron-probe microanalyser. Comparison with blanks prepared under identical conditions, but not fatigue tested, revealed a significant difference in the silver concentration and penetration and showed the diffusion rate during fatigue to be considerably increased. Calculation shows that the diffusion activity in the fatigue specimen was equivalent to that which would have occurred had the specimen been simply heated to $300^{\circ} \mathrm{C}$ for the duration of the test, namely, $60 \mathrm{~h}$. Several microanalyser traces were taken in different grains to allow for the orientation dependence of the diffusion process and the averaged results are displayed in Fig. 1.

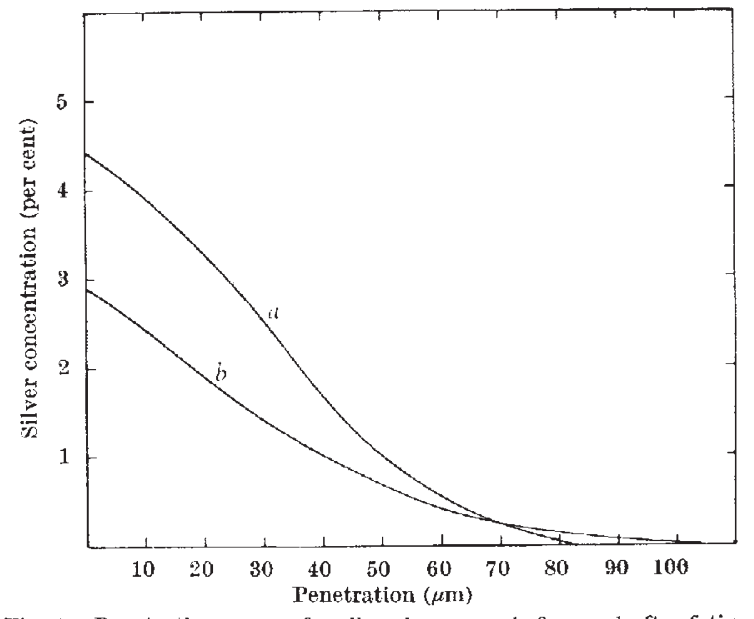

Fig. 1. Penetration curves for silver in copper before and after fatigue testing. $a$, Normal; $b$, after fatigue testing

Normally, long-range diffusion phenomena do not occur in copper at room temperature because the concentration of vacancies in thermal equilibrium in the crystal lattice and also the jump frequency are too low to facilitate appreciable movement of the atoms. The explanation of this phenomenon would appear to lie in the abnormally high vacancy concentration being produced during fatigue. The presence of a concentration gradient of silver in the surface layer of the copper has given directionality to the increased atomic movement and enabled a measure of this effect to be made.

Previous attempts ${ }^{2}$ to measure an enhanced diffusion rate due to plastic deformation have been pursued in tests at temperatures well above room temperature where normal thermal diffusion rates have been appreciable. It is considered that the much larger rates of diffusion in these tests overshadowed the changes produced due to excess vacancy concentration and led to the confusion regarding the occurrence of this phenomenon.

The results obtained here are in keeping with observations made in irradiated materials ${ }^{3}$ where diffusion changes have becn detected and the cause been attributed to excess vacancy concentration. These measuremonts were achieved by detecting changes in short-range phenomena, such as ordering in certain alloy systems, and showed a similar equivalent temperature dependence.

The importance of this type of measurement lies in the fact that this is the first method yet realized where measurement of the mobility of atomic defoets, important to the fundamental mode of fatigue failure in metals, has been made possible and should allow eventually a physical description of the process leading to crack initiation during fatigue.

W. J. DERRICK JONHS W. D. DOVER

Department of Mechanical Enginecring,

University ('ollege, London, Gower Street, W.C.1.

s Ballufli, R. W., and Ruoff, A. L., $J$. App. Phys., 34, 1634, 1848, 2862 (1963). ${ }^{2}$ Pearson, S., Board, A. J., and Wheeler, C., Roy. Aircraft Estab. Rep. No. Met. 94 .

${ }^{3}$ Dienes, G. S., and Damask, A. C., J. A pp, Phys, 29, 1713 (1958). 